\title{
The Role of Psychological Empowerment in Open Innovation
}

\author{
Zhenxing Gong \\ School of Business \\ Liaocheng University \\ Liaocheng, China \\ zxgong163.com
}

\author{
Zanzan Zhao \\ School of Business \\ Liaocheng University, \\ Liaocheng, China \\ 1052887341qq.com
}

\author{
Shuo Wang* \\ School of Business \\ Liaocheng University \\ Liaocheng, China \\ 37582528qq.com \\ *Corresponding author
}

Haoyun Yu

School of Business

Liaocheng University

Liaocheng, China

1686926382qq.com

\begin{abstract}
Open innovation is a new mode to adapt to the innovation management reform. However, in the past, factors affecting open innovation were mostly analyzed from the macro and middle level, while the role of internal micro level was neglected. Based on the theory of construction and social exchange, this paper discusses the role of employee psychological empowerment in open innovation. The research conclusion is helpful to understand the micro-mechanism generated by open innovation in a more detailed way, and discover the mechanism and boundary conditions of the role of empowerment, feedback and ability in open innovation.
\end{abstract}

Keywords-Open innovation; Psychological empowerment; Feedback environment; Exchange of information

\section{INTRODUCTION}

Innovation is the source for enterprises to gain competitive advantages. However, the traditional innovation model, which emphasizes independence and closed completion, is facing the problems of shortening innovation cycle, significantly increasing $r \& d$ investment and accelerating knowledge transfer [1]. The new model of innovation management emphasizes the information connection between different organizations and the openness of information technology, so the researchers put forward the concept of open innovation. Open innovation refers to the innovation mode in which enterprises cross organizational boundaries, integrate internal and external information and technologies to promote internal innovation, and apply internal innovation to external applications by expanding the market. Chesbrough and Crowther classified open innovation into inbound open innovation and outbound open innovation. The inward open innovation means that the enterprise applies external knowledge and technology to internal research and development. Extroverted and open innovation refers to the enterprise seeking for appropriate

This research was supported by grants from the National Natural Science Foundation Youth Science Fund of China(71801120),the Ministry of Education of Humanities and Social Science Research youth fund project(18YJC630038), Shandong Social Science Planning Fund Youth Program(18DGLJ02) external organization commercial utilization of internal knowledge or technology [2].

As innovation has always been regarded as enterprise behavior and research and development is also an innovation competition among enterprises, the former cause of open innovation focuses more on the enterprise level. However, the purchase, external contact and sale of enterprise leaders or employees are all positive attitudes towards open innovation [3]. Therefore, individual factors in open innovation should be the focus of attention. Dahlander and Gann pointed out that since open innovation is a challenge to traditional innovation model, enterprises need to adopt new management methods to adapt to the change of innovation model. As a kind of management change, leadership change has become a key factor to cope with innovation management change. According to contingency theory, the effectiveness of leadership depends on the internal and external environment and the goals set. Previous studies that only focused on internal innovation found that transactional leadership, guided leadership and loathing leadership, which emphasize control, compliance and low flexibility, would hinder innovation. Modern innovation management emphasizes the openness of enterprise innovation, so it is necessary to explore how to lead effectively to promote open innovation [4]. Open innovation emphasizes the role of human capital in the selection, acquisition, transformation and application of innovative information. Therefore, open innovation requires leaders to effectively manage human capital, encourage followers to participate in information exchange, and trust and encourage followers to participate in innovation activities. Empowering leaders precisely have the above characteristics. West and Bogers believe that the open innovation of an enterprise is explained, decided and implemented by employees. Similarly, for the authorized leaders, how employees understand and perceive the empowerment behavior of the authorized leaders, forming the construction of the empowerment behavior directly affects the behavior of employees. Psychological empowerment is a 
synthesis of individual experience of the empowerment behavior, including four dimensions of meaning, self-efficacy, self-determination and influence [5]. Although previous studies have emphasized the role of empowerment in innovation, it is an important but neglected problem to explore the influence path of employees' psychological empowerment on open innovation. Therefore, this study will explore the role of employee psychological empowerment in open innovation.

Based on the above analysis, this study uses questionnaire survey to study the influence of psychological empowerment on open innovation (introversion open innovation and extroversion open innovation).

\section{THEORETICAL BACKGROUND AND RESEARCH HYPOTHESIS}

\section{A. Psychological empowerment and inbound open innovation}

Inward open innovation is an innovation that extracts, evaluates and integrates valuable external information and resources into internal systems and processes. This process needs to identify and determine which potential resources can be utilized and tested to serve the innovation strategy of the organization. Therefore, enterprises need knowledgeable, motivated, confident and independent employees to promote the generation of new knowledge and new technology. Leadership plays a key role in motivating employees to complete given tasks, which also includes introverted and open innovation. For inward, open innovation, leaders need to support followers to create and capture new ideas, and combine those ideas with internal systems and processes. In various leadership styles, empowering leaders are considered to have confidence and trust in followers, encourage followers to use participatory decision-making and motivate them to perform better. Empowering leadership is characterized by inspiring followers to explore innovative ideas, including leading by example, participatory decision-making, guidance, notification, and caring for members. This kind of leadership presents a vision for employees and indicates that employees are expected to make greater contributions to organizational goals [6], which will improve employees' psychological empowerment, which directly determines the effectiveness of the delegated leadership.

Psychological empowerment built by followers instills confidence in followers and enables them to participate in knowledge-based activities, thus helping to achieve organizational goals. High psychological empowerment of employees can improve self-determination and influence at work, which will enhance the motivation of followers to share their thoughts and cooperate with each other, thus promoting effective knowledge flow. By rewarding, clarifying role expectations, and allowing followers to make their own decisions, the leader can improve the psychological empowerment of employees, and the followers can perceive more interpretations of work meaning from the leader, and increase work autonomy, influence and efficacy. At the same time, psychological empowerment also increases interpersonal trust, which enables followers to effectively communicate, understand market trends, constructively evaluate external market opportunities, and evaluate the expected benefits of acquiring external knowledge. In turn, this environment of trust extends followers' ability to integrate external knowledge into organizational processes. It also means that the organization allows employees to take risks and tolerate failure, which is an important condition for innovation. Research has shown that empowerment and trust have a positive impact on both individual and corporate innovation capacity. Khazamchn et al. pointed out that innovation requires flexibility, empowerment, control and efficiency. Psychological empowerment is a kind of supportive culture, structure and system in the organization that followers feel, thus producing good organizational results. Based on the above analysis, the following hypothesis is obtained:

Hypothesis 1: psychological empowerment positively influences introverted and open innovation.

\section{B. Psychological empowerment and outbound open innovation.}

Outbound open innovation refers to the commercial utilization of external organizations by seeking for appropriate internal knowledge or technology. Employees with high psychological empowerment can feel that the leadership will reshape the trust and information of employees and allow employees to explore all possible options for innovation. Employees with high psychological empowerment have a strong sense of self-efficacy, can control work goals and direction, and can feel the leader's expectations of followers to develop new ideas through experiments in work practice, even if such pursuit is risky. In the process of supporting innovative ideas and solutions, employees discover, through psychological empowerment, the risk-taking behaviors that leaders exhibit related to the implementation of new ideas and technologies. In addition, by allowing employees to participate in decision-making based on their own knowledge and experience without direct intervention of the leader [46], leaders can improve the psychological empowerment of employees, thus promoting activities based on knowledge exchange. Employees with high psychological empowerment make behavioral changes through role determination, and leaders encourage followers to effectively use knowledge through recognition, recognition and reward.

Based on the above arguments, it can be inferred that psychological empowerment increases the initiative and autonomy of employees as followers, and makes employees feel the recognition of employees' knowledge, technology and ability by leaders, bringing new ideas, perspectives and technologies generated within the organization to the external market and commercialization. Such activities often reinforce a company's strategic position and ensure optimal alignment of its resources with its goals. This in turn leads to effective management of knowledge outflow, thus promoting innovation in opening up to the outside world. Based on the above analysis, the following hypothesis is obtained:

Hypothesis 2: psychological empowerment positively affec ts extroverted and open innovation

\section{RESEARCH DESIGN}

This study selected 350 employees from the department technology department, Marketing Department, finance department, sales department and human resources department 
of 15 industrial enterprises in three provinces including Shandong province, Jiangsu province and Guangdong province as the research object, and completed this horizontal study through on-site distribution and on-site recycling. Among them, 315 valid questionnaires are $90 \%$ of the participants. Among them, there were 182 cases of male and 133 cases of female, accounting for $57.8 \%$ and $42.2 \%$ of the total sample. There were 175 cases, accounting for $55.6 \%$, with the age of 35 or less. 196 cases with a working age of 5 years or less accounted for $62.2 \%$. The education level was higher in 231 cases, accounting for $73.3 \%$.

Psychological empowerment. The psychological empowerment scale adopts the questionnaire with 12 questions prepared by Spreitzer, such as "I have great independence and autonomy in how to complete the work", which is the 7-point Likert scale. As in previous studies, this study only considered the overall psychological empowerment level and recorded the average value of all subjects as the psychological empowerment level. Cronbach's interval coefficient was 0.87 .

Inward and open innovation. The introverted open innovation scale Sisodiya was used, containing six topics, such as "my organization considers it useful to use external resources. For example, research groups, universities, suppliers, customers, competitors, etc. 7 points Likert scale. Cronbach's coefficient was 0.91 .

Open innovation. The extroverted open-innovation scale, developed by the researchers, contains four topics, such as "my unit seeks technology and patents from other companies, research groups or universities". 7 points Likert scale. Cronbach's coefficient was 0.93 .

\section{RESEARCH RESULTS}

TABLE I lists the standard deviation and mean value of each variable and the correlation between them. It is found that psychological empowerment is significantly positively correlated with introverted open innovation $(\mathrm{r}=.65, \mathrm{p}<.01)$ and extroverted open innovation $(\mathrm{r}=.57, \mathrm{p}<.01)$.

TABLE I. THE MEAN VALUE, ST ANDARD DEVIATION AND CORRELATION COEFFICIENT MATRIX OF VARIABLES

\begin{tabular}{ccccc}
\hline & The mean & The standard deviation & & \\
\hline $\begin{array}{c}\text { 1.Psychological } \\
\text { empowerment }\end{array}$ & 5.01 & 1.37 & - & \\
$\begin{array}{c}\text { 2.inbound open } \\
\text { innovation }\end{array}$ & 4.44 & 1.69 & $.65^{* *}$ & $.64^{* *}$ \\
$\begin{array}{c}\text { 3.outbound open } \\
\text { innovation }\end{array}$ & 3.98 & 1.856 & $.57^{* *}$ & $.43^{* *}$ \\
\hline
\end{tabular}

Hypothesis 1 and 2 are intended to verify the direct effect of psychological empowerment on open innovation. According to model 1 and 4 in table 2, the psychological empowerment of independent variables has a significant impact on the inbound open innovation $(\beta=.80, \mathrm{p}<.01)$ and the outbound open innovation $(\beta=.78, \mathrm{p}<.01)$. Hypothesis 1 and hypothesis 2 are verified.

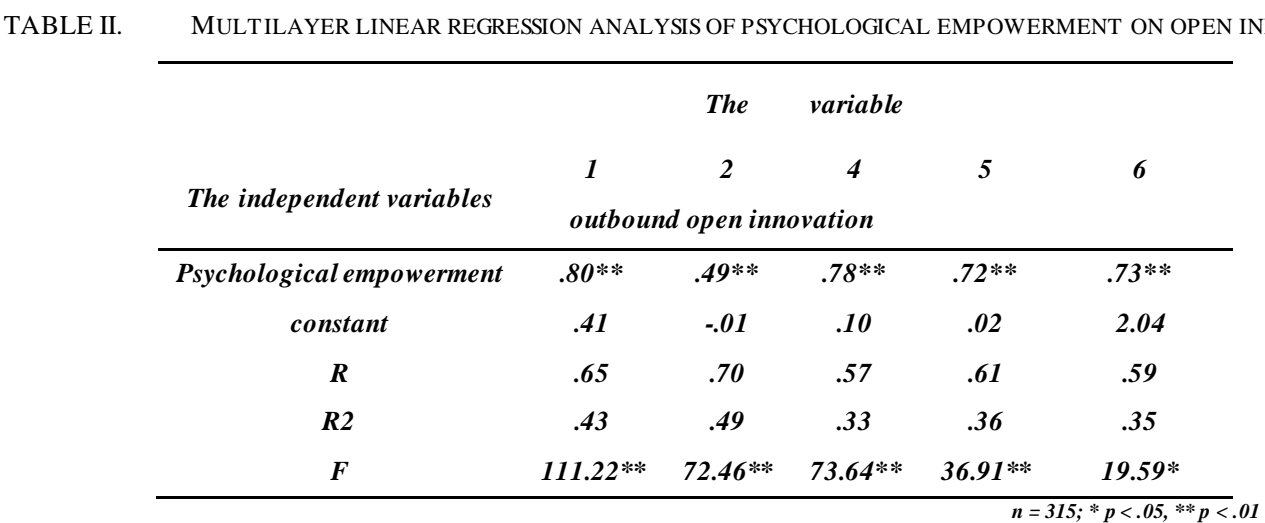

After introducing independent variable psychological empowerment into equation to predict inward open innovation and outward open innovation, through multiple linear regression analysis, it is found that the influence of independent variable psychological empowerment on inward open innovation (model 2, beta $=.49, \mathrm{P}<0.01$ ) and outward open innovation (model 4 , beta $=.72$, $\mathrm{P}<0.01$ ) is smaller, which is in line with Baron and Kenny's theory. Part of the intermediary standard.

\section{CONClUSION}

The purpose of this study is to explore the effect of psychological empowerment on open innovation (introversion and extroversion).
This study is a study in the context of China, providing support for innovation-driven growth and entrepreneurship from the micro level for a series of measures of mass innovation and entrepreneurship. Consistent with Curan and Blacburn, in order to achieve economic development, creation, application and introduction of innovation must be realized at different levels (individuals, organizations and countries) [7]. As the open innovation paradigm has gained more and more popularity and acceptance worldwide, its application in the Chinese context can provide new progress for the open innovation model. Inter-organizational collaboration among stakeholders is the essence of open innovation, because the cooperation brought about by open innovation can reduce innovation and spending, which is especially important for the economic success of emerging economies such as China. 
Most of the hypotheses in this study are empirically supported. Psychological empowerment promotes introverted and outbound open innovation. Employees have a strong sense of psychological empowerment and perceive that leaders encourage followers to carry out activities related to creation and acquisition of knowledge, so as to achieve higher introverted and open innovation results. The employee believes that the leader focuses on and shapes the behavior and attitude that the leader wants, and motivates the employee to seek new knowledge and new ideas in the external market. This finding is consistent with previous studies that found that leadership empowerment promotes innovation. Research shows that innovation requires employees to feel empowered, empowered and motivated to make decisions independently. However, psychological empowerment style contains these necessary factors, for example, high psychological empowerment may promote knowledge acquisition and adoption, thus leading to higher introverted and open innovation results. In addition, companies with high levels of psychological empowerment manage their knowledge outflow more effectively. Employees with high levels of psychological empowerment are in an environment that encourages them to leverage knowledge inflows and/or develop internal resources through external licensing in external markets. With empowering leaders' trust and confidence in their followers, enthusiastic followers show risk-averse behavior, thus performing better in innovative activities.

\section{THEORETICAL AND PRACTICAL CONTRIBUTIONS}

Based on the comprehensive model of open innovation, this study makes contributions to theory and practice. The results of this study could provide a new perspective for China's corporate management decision-makers and help them achieve their innovation-driven growth and development. This research extends the research in the field of open innovation. In addition, it clarifies the correlation process and condition factors between psychological empowerment and open innovation, and proposes a new perspective for the open innovation field.

This study pays attention to the formation mechanism of open innovation from the micro level, and breaks through the previous deficiencies that only focus on the macro and middle level, and provides a basis for enterprises to improve the soft power of open innovation. This study found the impact of psychological empowerment on open innovation. Although the existing literature emphasizes the role of leadership in shaping innovation, this study further explores and combines the previous leadership research with the construction theory to analyze the role of empowering leadership, that is, psychological empowerment level, built by employees in open innovation.

From the perspective of management practice, this research can provide a new perspective for decision makers. From the perspective of enterprise micro-management, managers can better understand the role of empowerment in promoting open innovation. They should not only play the role of empowering leaders at the leadership level, but also pay attention to the empowerment perceived by employees.

\section{LIMITATIONS AND FUTURE PROSPECTS}

One of the shortcomings of this study is that all the data are from the self-assessment questionnaire. This kind of data collection method may produce common method variation, although some measures have been taken in procedure and data processing to overcome the problems caused by common method variation. For example, all participants were told to fill in anonymously, and there was no right or wrong choice. In overcoming common method variations of homologous data, more attention should be paid to how variables are measured and how this particular variation affects the relationships between variables. In future studies, more objective tools for measuring open innovation should be found to accurately reflect true open innovation or to focus on the relationships between variables that are susceptible to variation.

\section{REFERENCE:}

[1] WEST J, BOGERS M. Open innovation: current status and research opportunities[J]. Innovation Management Policy \& Practice, 2017,19(1)43-50.

[2] CHESBROUGH H, BOGERS M. Explicating Open Innovation: Clarifying an Emerging Paradigm for Understanding Innovation[J]. Social Science Electronic Publishing, 2014,1:3-28.

[3] LICHTENTHALER U. Open Innovation: Past Research, Current Debates, and Future Directions[J]. Academy of Management Perspectives, 2011,25(1):75-93.

[4] KROGH G V, HIPPEL E V. Special issue on open source software development[J]. Research Policy, 2003,32(7):1149-1157.

[5] SPREITZER G M, JANASZ S C D, QUINN R E. Empowered to lead: the role of psychological empowerment in leadership[J]. Journal of Organizational Behavior, 1999,20(4):511-526.

[6] CONGER J A, KANUNGO R N. Charis matic leadership: the elusive factor in organizational effectiveness[J]. Administrative Science Quarterly, 1988,35(4):732.

[7] CHESBROUGH H, WEST J. Open Innovation: Researching a New Paradigm[J]. Wim Vanhaverbeke, 2006, volume 84(April):1259. 